\title{
Biliary Complications Following Orthotopic Liver Transplantation: the Place of Surgical Reconstruction in the Minimally-Invasive Era
}

\author{
Octavio A. Gil*, Rodrigo Figueroa, Maximiliano Yance, Franco Pascual, Joaquín Bastet, \\ Rogelio A. Traverso, Carlos H Valenzuela
}

\author{
${ }^{*}$ Corresponding author: \\ Octavio A Gil, MD PhD MAAC \\ Liver and Pancreas Transplantation \\ Unit - Sanatorio Allende - National \\ University- Obispo Oro 42 ZIP 5000 \\ Cordoba- Argentina \\ Tel: 543514811413 \\ Fax: 543514811011 \\ E-mail: octavioagil@gmail.com
}

Liver and Pancreas Transplantation Unit Sanatorio Allende, National University, Cordoba, Argentina

\section{ABSTRACT}

Background: Biliary complications are the more frequent problem following liver transplantation (LT) and have been considered the "Achiles's heel" of this procedure. The aim of this study was to evaluate the rates of biliary complications after LT, the different therapeutic modalities currently available and their outcomes.

Methods: A total of 420 LTs performed up to 2020 were retrospectively analyzed. Evaluation factors included MELD score, images, surgical techniques, type of biliary reconstruction and type of complications. We also analyzed the different therapeutic options, and the short and long-term outcome.

Results: 417 deceased donors and 3 living donor transplants were performed. Biliary complications occurred in 37 patients $(8,8 \%)-31$ strictures $(81 \%)$, four leaks $(11 \%)$, one acute biliary peritonitis after T-tube removal (3\%) and two patients biliary stones (5\%). Biliary complications associated with vascular complications were seen in 10 patients (27\%). In general, a minimally invasive management (percutaneous or endoscopic) was the first-line approach. Percutaneous interventional procedures were the treatment of choice in $32 / 37$ patients $(86,48 \%)$, with a success rate of $67.74 \%(21 / 31)$. Hepaticojejunostomy (HJ) was performed in 14 patients. Overall morbidity rate of surgical reconstruction was $14 \%(2 / 14$ patients) and perioperative mortality was $7 \%$. The median follow-up was 54,53 months. At follow-up, none of the patients in the $\mathrm{HJ}$ group had developed a new stricture.

Conclusions: The majority of biliary complications must be treated by minimally invasive approach. However, when those fail,surgical reconstruction allows to avoid future consequences in the graft.

Key words: biliary complications, orthotopic liver transplantation, biliary strictures, biliary leaks

\section{INTRODUCTION}

Liver transplantation (LT) is currently the standard therapeutic procedure both for patients with end-stage liver disease and with acute liver failure. Surgical techniques, immunosuppression, and postoperative management have steadily improved resulting in better patient outcomes. However, complications involving the biliary tract continue to be a frequent problem after transplanta- 
tion. The most common biliary complications (BC) are biliary strictures (BS) and biliary leaks (BL), and the estimated incidence ranges between 6 to $35 \%(1,2,3,4)$. These complications often result in surgical reinterventions, hospital readmissions, higher costs, and contribute to significant morbidity and mortality rates. These complications are seen both in deceased donor liver transplant (DDLT) and living donor liver transplant (LDLT), although they are more frequent in the latter $(2,5,6,7)$. Treatment modalities will depend on the type and severity of the complication, and the type of biliary reconstruction used at the time of the LT, Duct to Duct anastomosis (D-D) or hepaticojejunostomy (HJ) (8). Minimally invasive (MI) treatment of $\mathrm{BC}$ with an endoscopic or a percutaneous approach has become a mainstay in the management of post-transplantation $B C$ (9), leaving the surgical intervention for a small proportion of patients in whom the $\mathrm{Ml}$ approach has failed. The success rate of the endoscopic approach reaches $80 \%$ in experienced hands $(9,10)$. If unsuccessful with endoscopy (11), percutaneous transhepatic management can be a good alternative therapy (12). Early identification and adequate treatment of recognized $B C$ following $\mathrm{LT}$ are fundamental in reducing the morbidity and mortality rates of this complication and ensuring graft and patient survival. The decision on which technique has to be employed therefore depends on the type of $B C$ and the experience in endoscopic or percutaneous approach, leaving surgical revision as the last option (12). The focus of this review will be the discussion on the types, diagnosis, and results of different treatment modalities for BC following LT and the current place of surgical reconstruction.

\section{MATERIAL AND METHODS}

In this study, we retrospectively reviewed the records of 420 liver transplantation in two different Centers, until 2020. The first period (1996-2004) at the Italian Hospital of Cordoba with 45 patients, and the second period at the Sanatorio Allende of Cordoba with 385 patients between 2005 and 2020 .

The Child-Pugh model and waiting time for liver graft allocation was used until 2005; afterwards the MELD score was used.

Patients follow-up was held in the transplant outpatients office at least once per month, and comprised physical examination, blood chemistry and images (US-TC-RM) when necessary.

The surgical technique employed for cadaveric and
LDLT was described by Starzl in $1963(13,14,15,16)$.

Venovenous bypass with pump and T-tube insertion was used only in the first 35 recipients. Since 2005, all procedures were performed with Piggy-Back Technique. The biliary reconstruction was usually performed as an end-to-end anastomosis between the donor common bile duct and the recipient common hepatic duct with interrupted or running 6-0 monofilament absorbable suture, polydioxanone (PDS; Ethicon, Somerville, NJ). When the indication for LT was a biliary disease (such as primary sclerosing cholangitis), when there was a marked discrepancy between the bile duct sizes, and during re-LT, we prefered to perform a Roux-en-Y HJ. Two to three closed-suction abdominal drains were routinely inserted.

Medical records of all patients who underwent liver transplantation were reviewed. The analyzed data included, age, sex, co-morbidity, indication of liver transplantation, cold and warm ischemia time, type of biliary complication and treatment modality used.

We defined $B C$ as strictures, leaks, or the presence of common bile duct stones. Furthermore, complication after T-tube removal was also considered as biliary complication. Anastomotic biliary strictures or bile duct stones were suspected in the presence of elevated serum bilirubin and/or alkaline phosphatase levels and confirmed by ultrasonography (US) or magnetic resonance (MR) cholangiography findings. Anastomotic bile leaks were diagnosed by the presence of bile in the abdominal drains, radiologic evidence of a leak, or the presence of an intra-abdominal biloma. T-tube related complications occurring after removal, developing biliary peritonitis. When a $B C$ was diagnosed on the basis of clinical suspicion (jaundice, pruritus), increased ALP, gGT and hyperbilirubinemia, biliary duct dilatation or stenosis at ultrasound and confirmed by MR imaging, we considered patients for an initial MI percutaneous or endoscopic approach, depending on the type of complication. The surgical revision was considered after failure of $\mathrm{MI}$ techniques or according to the type of complication.

Follow-up for non surgical therapy was 21 months (1 to 111) and for surgical approach was 54,53 months.

All quantitative data are expressed as median (range). Qualitative data are expressed as numbers (\%). The Mann-Whitney $U$ test for continuous variables and Pearson's chi-square test were used when applicable, or Fisher's exact test for categorical variables. Statistical analyses were performed using SPSS 20.0 (SPSS Inc, Chicago, IL, United States). A p-value of less than 0.05 was considered statistically significant. 


\section{RESULTS}

Patient demographics of the study group and primary liver disease of patients undergoing LT are presented in table 1. Etiology of LT in patients with biliary complication are listed in table 2 .

Of the total cohort, duct-to-duct (D-D) biliary anastomosis was performed in 379 transplants (90\%), whereas a Roux-en-Y HJ was done in 41 patients because of primary disease of the bile ducts (sclerosing cholangitis or primary biliary cirrhosis), or due to biliary duct disparity.

The mean age of recipients in the entire cohort was 38 years old (range 6 to 71 ).

Mean age of the $B C$ group was 55 years (range 16 to 70 years). A total of $19(54,28 \%)$ were males and 16 females.

University of Wisconsin (UW) preservation solution was used in $372(88,58 \%)$ cases and HTK in $48(11,42 \%)$; 28 patients in whom UW solution was used presented a BC whereas 9 out of $48(18,75 \%)$ patients in the HTK solution group were associated with this complication $(\mathrm{p}=0.02)$.

Three hundred and eighty-five patients $(91,66 \%)$ were listed according to the MELD score on an average value of 27 (range 21-30). Mean Meld score in complicated patients was 30 (range 23-38) (NS).

Mean cold ischemia time (CIT) in the BC group was 7,42 hours, and warm ischemia time (WIT) 35 minutes, without significant differences with the control group. In the BC group, five out of 37 had more than 9 hs of $\mathrm{CIT}$ and 32 out of 37 had less than $8 \mathrm{hs}$.

Thirty-seven patients presented some type of BC, with an overall rate of $8.8 \%$. Thirty-one patients presented with a BS (81\%), six with anastomotic leaks (AL), out of which four were associated with biloma and two ultimately developed a BS; one patient suffered from an acute biliary peritonitis after T-tube removal and two patients had common bile duct lithiasis, one of them in the context of a BS. None of them was associated with HCC.

Biliary complication associated with vascular complication was seen in 10 out of 37 (27\%).

The mean time between LT and the occurrence of a $\mathrm{BC}$ was 130 days for $\mathrm{BS}$ and 60 days for $\mathrm{AL}$ (table 3).

Management overview of $B C$ patients is presented in fig. 1.

The initial management of patients with $\mathrm{BC}$ was a percutaneous approach in $32(86,46 \%)$ recipients. A Rome Protocol was indicated in three of these patients $(9.37 \%)$ because of failure of primary percutaneous dilatation.
Table 1 - Indications in $\mathbf{4 2 0}$ Liver Transplantations - HCC was associated in 19 patients

\begin{tabular}{|c|c|c|c|}
\hline Etiology & & & $\%$ \\
\hline alcoholic & 110 & 5 & $26,19 \%$ \\
\hline autoimmune & 79 & 1 & $18,80 \%$ \\
\hline HCV & 47 & 6 & $11,19 \%$ \\
\hline Criptogenetic & 44 & & $10,57 \%$ \\
\hline NASH & 27 & 4 & $6,47 \%$ \\
\hline FHF & 27 & & $6,47 \%$ \\
\hline $\mathrm{PBC}$ & 26 & & $6,19 \%$ \\
\hline Haemochromatosis & 26 & 3 & $6,19 \%$ \\
\hline Cr. Rejection & 9 & & $2,14 \%$ \\
\hline SBC & 6 & & $1,42 \%$ \\
\hline EC & 6 & & $1,42 \%$ \\
\hline HBV & 5 & & $1,19 \%$ \\
\hline H. Art.Trom & 2 & & $0,47 \%$ \\
\hline Budd Chiari & 2 & & $0,47 \%$ \\
\hline Caroli & 2 & & $0,47 \%$ \\
\hline hemangioendothelioma & 1 & & $0,23 \%$ \\
\hline
\end{tabular}

Table 2 - Etiology of liver transplantation in patients with biliary complication. None of them had HCC

\begin{tabular}{lcc}
\hline Etiology & Total & $\%$ \\
\hline autoinmune & 9 & $5,71 \%$ \\
\hline alcoholic & 7 & $20 \%$ \\
\hline Hemochromatosis & 3 & $8,57 \%$ \\
\hline Criptogenen & 3 & $8,57 \%$ \\
\hdashline PBC & 3 & $8,57 \%$ \\
\hline NASH & 3 & $8,57 \%$ \\
\hline VHC & 3 & $8,57 \%$ \\
\hline 2 CB & 3 & $8,57 \%$ \\
\hline Fulminant & 1 & $2,85 \%$ \\
\hline
\end{tabular}

Table 3 - Summary of patient characteristics

\begin{tabular}{|c|c|c|}
\hline & Complicated & Not Complicated \\
\hline Age/year & $55(16-70)$ & $38(6-71)$ \\
\hline Sex & F/M 147/236 & $\mathrm{F} / \mathrm{M} \quad 17 / 20$ \\
\hline Meld Score & $30(23-38)$ & $27(21-30)$ \\
\hline Preservation Solution & UW/HTK 28/9 & UW/HTK $344 / 39$ \\
\hline Cold Ischemia Time & $\begin{array}{c}7 \text { hs } 42^{\prime} \\
\text { (2hs } 46^{\prime}-10 \text { hs } 40^{\prime} \text { ) }\end{array}$ & $\begin{array}{c}7 \text { hs } 50^{\prime} \\
\text { (5hs 50'-10hs 55') }\end{array}$ \\
\hline Warm Ischemia Time & $35^{\prime}(18-56)$ & $33^{\prime}(19-35)$ \\
\hline
\end{tabular}

The standard $\mathrm{Ml}$ approach consisted of an initial percutaneous transhepatic drainage (PTD) followed by sequential balloon dilatations as required. In general, two to four procedures were needed, with an average of two dilatations per patient. There was no morbidity in the PTD group but one patient died as consequence of a duodenal perforation after the procedure.

The percutaneous management was successful in 


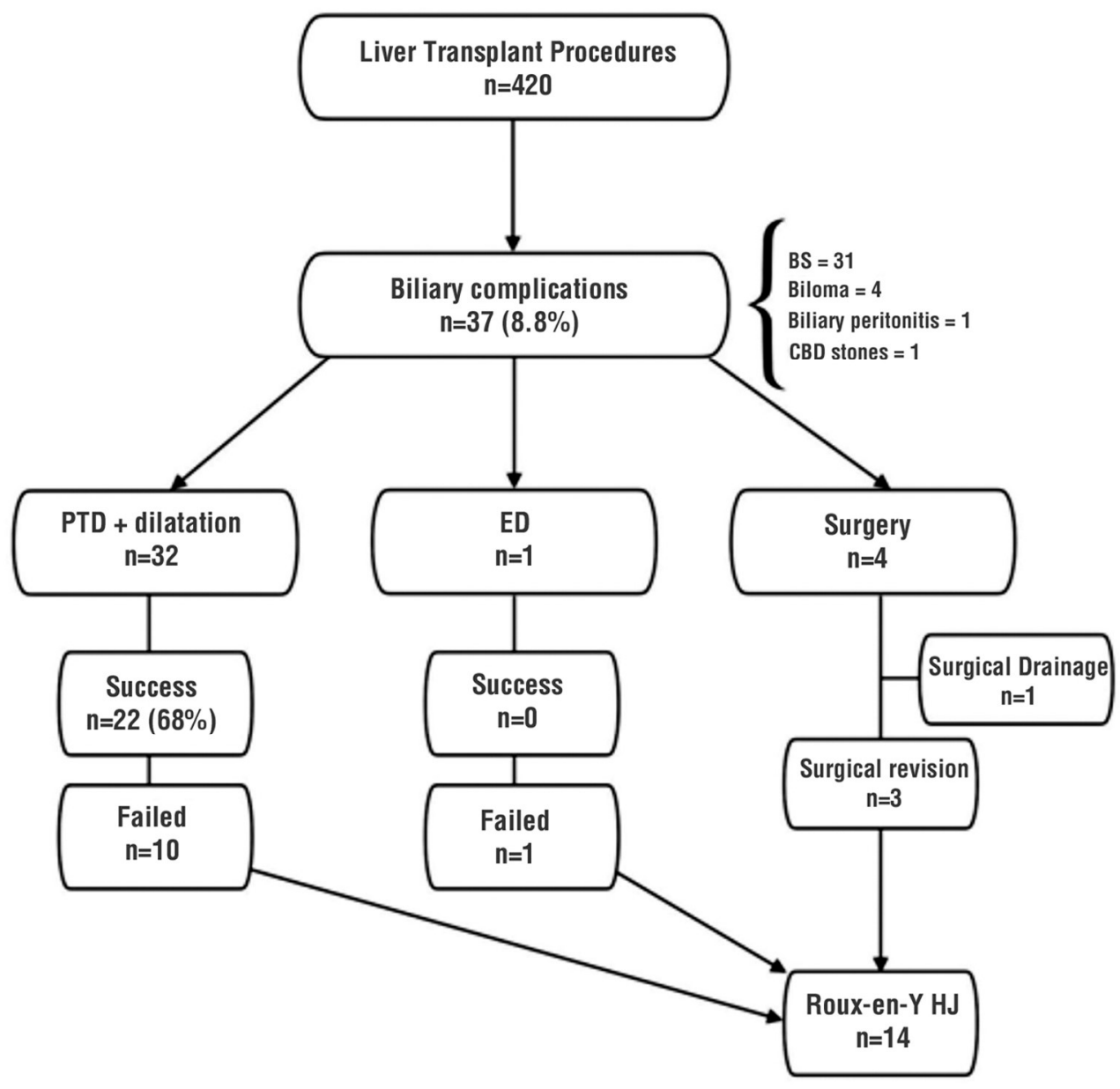

Figure 1 - Management overview of biliary complications after LT. Abbreviations: BS, biliary stricture; CBD, common bile duct; PTD, percutaneous transhepatic drainage; ERCD, endoscopic drainage; $\mathrm{HJ}$, hepaticojejunostomy.

22 of the 32 patients (68,7\%). Mean follow-up was 21 months (1 to 111).

Endoscopic treatment was performed in one patient. The indication for this approach was a nonanastomotic stricture associated with cholangitis. This patient eventually underwent an $\mathrm{HJ}$ because of persistence of the stricture.

One patient who presented with biliary peritonitis after T-tube removal only required an exploratory laparotomy and drainage of the abdominal cavity.

In total, 14 of $37(38 \%)$ patients underwent an $\mathrm{HJ}$. Ten patients in whom the PTD had failed, one for failure of the endoscopic approach, and as initial treatment in three patients, who presented with CBD stones and BS $(5,4 \%)$. The morbidity rate after surgical revision was $14 \%(2 / 14)$; one of these patients presented an anastomotic leak and the second one presented an intrahepatic infected hematoma requiring percuta- neous drainage. one patient died after the procedure due to septic complications (mortality rate of $7 \%$ ). Median follow-up of HJ was 54,53 months (range 1 to 120 months). At follow-up, none of the patients in the $\mathrm{HJ}$ group had developed a new stricture.

No patient needed a re-transplantation because of therapeutic failure of the involved techniques.

\section{DISCUSSION}

Complications involving the biliary tract remain a common problem following orthotopic LT and can potentially lead to graft failure with significant morbidity and mortality rates.

Out of 420 LT performed in the study period, 37 $(8,80 \%)$ suffered from a $B C$ during follow up. In the reported literature, the incidence of this complication ranges from $6 \%$ to $35 \%(1,2,3,4)$. We believe that 
our low incidence regarding $B C$ is the small number of LDLT as well as split liver procedures, which are known risk factors for developing this complication $(6,17,18,19,29,39)$.

There were no differences in the MELD score between patients with and without biliary complication (20). But when we compare before and after MELD score adoption, we observethat the rate of biliary complications has increased with the adoption of the MELD (21).

Regarding CIT and WIT, we do not have significant differences between complicated patients and those without complication. In previous reports, only a WIT> 49 minutes has been associated with AL (22), and the mean WIT of our cohort was 35 minutes, which can explain why there were no differences.

Foley et al and Axelrod et al. described donation after Cardiac Death Donors as a risk factor for BC, but this is not still regulated in our country $(21,23,24)$.

We prefered D-D biliary anastomosis except when the indication of LT was biliary disease. The nontraumatic, running or interrupted suture, with monofilament absorbable material is the technique of choice for end- to-end ductal anastomosis (32). However Esfeh et al. report comparable outcomes between D-D and $\mathrm{H} J$ in selected PSC patients (25). Kaldas et al. reported in 2019 that non absorbable suture is an independent risk factor to $\mathrm{BC}$ (26).

Around $70 \%$ of $\mathrm{BC}$ occurs in the first year after $\mathrm{LT}$ (27); however it may appear up to several years after transplantation. In our study, the median time from LT to the occurrence of $B L$ was 60 days (15-120) and 130 (30-400) days for BS.

BS were the predominant complication in 31 of 37 patients (81\%); four patients had simultaneous $\mathrm{BL}$ and biloma, and two had BL and stricture. One patient presented acute biliary peritonitis after $\mathrm{T}$ tube removal for that reason T-tube was assessed as a risk factor, and its use has been rejected.

BS can be presented as Anastomotic strictures (AS) that account for $80 \%$ of all strictures, and Non anastomotic strictures (NAS) represented by $20 \%(28,29)$.

AS are more prevalent with Roux-en-Y $\mathrm{HJ}$,and are more commonly seen after LDLT than DDLT, because the anastomoses in living donor recipients are made between multiple small bile ducts (30). Usually, they occur in the first 12 months, they tend to be short and localized to the anastomotic site, opposite to NAS that typically occur in multiple sites and are longer in length (31). Pathophysiological factors can be local tissue ischemia, localized edema and fibrosis at the site of the biliary anastomosis (5).
NAS are strongly associated with hepatic artery thrombosis, ischemic damage to the duct or because of immunological factors $(32,33)$. NAS can occur in both the extra- or intrahepatic ducts and average time to development is usually 3 to 6 month $(32,34,36)$.

The biliary tree is supplied solely by the peribiliary vascular plexus which arises from the hepatic artery, through a network of arterioles and capillaries known as the peribiliary vascular plexus. Those vessels are usually ligated during OLT; for these reasons NAS can be attributed to ischemic phenomena (37). Others researchers also found that periductal vascular injury may be a cause of complication $(5,38)$. In our study, the association with vascular problems was $27 \%$.

The diagnosis of biliary complication after LT may be achieved through the use of a variety of imaging modalities, including ultrasound (US), magnetic resonance imaging (MRI), endoscopic retrograde cholangiography (ERC) or percutaneous transhepatic cholangiography (PTC) $(5,39,40)$. We have used preferably US as the first study because of its availability, low cost as well as the valuable information about liver vasculature with US-Doppler. Several reviews of the use of contrast-enhanced ultrasound (CEUS) in liver transplantation have been published. On CEUS, the intra and extrahepatic bile duct can be seen as radiographic cholangiography.CEUS appears to be a good test for the visualization of the bile ducts of liver grafts (41). MRI with cholangiopancreatography is used when we suspect biliary complication after US. Furthermore, MRI provides cross-sectional imaging of the liver and intraabdominal structures, allowing the detection of a variety of postoperative problems. MRI with cholangiography is the most effective non-invasive imaging modality for the assessment of BC after LT, with a sensitivity and specificity for the diagnosis $\geq 90 \%$ $(28,35,42)$. Treatment strategies for BC are based on the type and severity of the complication and the biliary reconstruction technique applied at the time of LT. A MI management, PTC or ERC, is currently the first-line approach $(1,4,34,43)$. These procedures should be considered complementary techniques, and success can be achieved in $70 \%-90 \%$ (1). However, some researchers reported that up to $50 \%$ of patients may present new strictures after $\mathrm{Ml}$ treatment (44). Choo et al. found that acute pancreatitis (21\%) and stent blockage (30\%) were the main complications after ERC (38). Percutaneous transhepatic management can be used successfully and may be performed to avoid further complications and additional surgical procedures $(3,6,45)$, also in pediatric patients $(45)$.

Biliary leaks can be treated conservatively by main- 
taining the abdominal drain if the patient's condition is stable. Cut surface leaks or small caudate duct leaks usually respond to the conservative approach and resolve in 5-8 weeks. Anastomotic leaks, however, require additional intervention. Patients with duct to duct anastomosis can be treated successfully with percutaneous approach $(2,20)$ or with ERC, with reported success rates of $80 \%-90 \%$ (28). Whereas small leaks can be managed by endoscopic sphincterotomy alone, management of significant anastomotic bile leaks may require stent placement with a success rate of approximately $50 \%$ (32). The remainder of cases require surgical revision, especially in early leaks or when the patients are unstable. Bilomas are usually treated by insertion of a percutaneous catheter with high rates of success $(32,34)$.

Second line treatment is PTD. This technique is generally performed when ERC is not feasible, because of a Roux-en-Y biliary enteric anastomosis, or when ERC has failed because of complex or tight strictures. Bile duct stone complications, especially after $\mathrm{HJ}$ are treated by a percutaneous approach (46)although Tsutsumi et al. report the success with both PTD and endoscopic procedures (20). Also, multiple endoscopic plastic stents are currently used in patients with BS of D-D anastomosis but are associated with an increased rate of pancreatitis $(32,47)$.

Although PTD has an overall technical success rate of $40 \%$ to $85 \%$, it remains a second-line therapy because of its potential complications, such as hemorrhage, bile leaks, and infection $(2 \%-14 \%)(47,48)$.

The risks of hemorrhage from PTD may be particularly problematic in patients with persistent thrombocytopenia or coagulopathy after transplant. Furthermore, there exists more discomfort for patients undergoing PTDdue to the presence of an external catheter throughout a course of treatment that can extend over many months. Despite the aforementioned, we preferthis method because we have achieved great expertise with it with a success rate of $68,7 \%$.

Surgical revision is now reserved for patients who have strictures refractory to either ERC or PTD and in whom retransplant is the last resort after all other treatment modalities have failed $(4,32)$.

When surgical revision is required for patients with a D-D anastomosis, the most commonly performed procedure is a Roux-en-Y HJ. If an $\mathrm{HJ}$ was performed initially because of PSC or another bile duct abnormality, then an attempt is made to reposition the bile duct graft to a better vascularized area (49). We performed $14 \mathrm{HJ}$ in $37 \mathrm{BC}(38 \%)$. In 11 patients due to failure of MI treat- ment; $14 \%$ of this group presented some complication, and one patient (7\%) died. Davidson et al. (12) reported an overall morbidity rate of $26 \%$ after revision $\mathrm{HJ}$ and a mortality rate of $6.5 \%$ which is in line with our own findings. The success rate in terms of anastomosis patency was $100 \%$, with a follow-up of more than 54 months. HJ has demonstrated to be a safe and effective procedure with short hospital stay and fast recovery $(12,16,17,50)$.

Even though the success rate with $\mathrm{HJ}$ is superior to MI techniques in terms of anastomosis patency, we think that the initial approach with a percutaneous treatment is justified given that our success rate with this technique is around $70 \%$, added to the known benefits of this approach, such as shorter length of stay, faster recovery and lower costs.

\section{CONCLUSION}

Biliary complications remain a frequent problem after LT and there are currently multiple treatment modalities. BS is the more common complication. Early recognition and adequate treatment are pivotal to reducing morbidity and mortality, improving patient and graft survival. MI management of these complications is the best initial approach; in our experience, PTD followed by balloon dilatation for BS is a very good alternative, with low complications rate and good long term results, but when these procedures fail, we recommend the surgical intervention to ensure the viability of the graft.

\section{Author contributions}

All authors contributed equally to these work.

\section{Conflict of interest}

There are no conflict of interest to disclose.

\section{REFERENCES}

1. Rönning J, Berglund E, Arnelo U, Ericzon BG, Nowak G. Long-term Outcome of Endoscopic and Percutaneous Transhepatic Approaches for Biliary Complications in Liver Transplant Recipients. Transplant Direct. 2019;5(3):e432.

2. Nakamura T, lida T, Ushigome H, Osaka M, Masuda K, Matsuyama T, et al. Risk Factors and Management for Biliary Complications Following Adult Living-Donor Liver Transplantation. Ann Transplant. 2017;22:665-670.

3. Jegadeesan M, Goyal N, Rastogi H, Gupta S. Biliary Stricture After Endotherapy Failure in Living Donor Liver Transplantation. J Clin Exp Hepatol. 2019;9:684-689

4. Gunawans N, McCall JL, Holden A. Biliary complications following orthotopic liver transplantation. HPB. 2011;13:391-399

5. op den Dries S, Westerkamp AC, Karimian N, Gouw AS, Bruinsma 
BG, Markmann JF, et al. Injury to peribiliary glands and vascular plexus before liver transplantation predicts formation of non-anastomotic biliary strictures. J Hepatol. 2014;60:1172-1179

6. Zimmerman MA, Baker T, Goodrich NP, Freise C, Hong JC, Kumer S, et al. Development, management and resolution of biliary complication after living and deceased donor liver transplantation: a report from the A2ALL consortium. Liver Transpl. 2013; 19: 259-267

7. Tang W, Qiu JG, Cai Y, Cheng L, Du CY. Increased Surgical Complications but Improved Overall Survival with Adult Living Donor Compared to Deceased Donor Liver Transplantation: A Systematic Review and Meta-Analysis. BioMed Res Int. 2020 Aug 24;2020:1320830.

8. Jablonska B. End to end ductal anastomosis in biliary reconstruction: indications and limitations. Can J Surg. 2014, 57;4: 271-277

9. Kaldas FM, Korayem IM, Russell TA, Agopian VG, Aziz A, DiNorcia J, et al. Assessment of Anastomotic Biliary Complications in Adult Patients Undergoing High-Acuity Liver Transplant. JAMA Surg 2019;154(5):431-439

10. Williams ED, DraganovPV.. Endoscopic management of biliary strictures after liver transplantation. World $\mathrm{J}$ Gastroenterol. 2009;15(30):3725-3733

11. Katz LH, Benjaminov 0, Belinki A, Geler A, Braun M, Knizhnik M Aizner S, et al. Magnetic resonance cholangiography for the accurate diagnosis of biliary complication after liver transplantation. Clin Transplant. 2010, 24:163-169.

12. Davidson BR, Rai R, Nandy A, Doctor N, Burroughs A, Rolles K. Results of choledochojejunostomy in the treatment of biliary complications after liver transplantation in the era of nonsurgical therapies. Liver Transpl 2000;6:201-6.

13. Starzl TM, Marchioro TL, Von Kaulla KN, Hermann G, Brittain RS Waddell WR. Homotransplantation of the liver in humans. Surg GynecolObstet 1963; 117:659-676.

14. Starzl TE, Iwatsuki S, Esquivel CO, Todo S, Kam I, Lynch S, et al Refinements in the surgical techniques of liver transplantation. Semin. Liver Dis. 1985;5:349-356

15. Starzl TE, Iwatsuki S, Van Thiel DH, Gartner JC, Zitelli BJ, Malatack JJ, et al. Evolution of liver transplantation. Hepatology. 1982;2(5) 614-36.

16. Tzakis AG, Todo S, Starzl TE. Orthotopic liver transplantation with preservation of the inferior vena cava. Ann Surg. 1989;210 649-652

17. Liu CL, Fan ST, Lo CM, Wei WI, Chan SC, Yong BH, et al. Operative outcomes of adult-to-adult right lobe live donor liver transplantation: a comparative study with cadaveric whole-graft liver transplantation in a single centre. Ann Surg. 2006; 243:404.

18. Gómez CM, Dumonceau JM, Marcolongo M, de Santibañes E, Ciardullo M, Pekolj J, et al. Endoscopic management of biliary complications after adult living-donor versus deceased-donor liver transplantation. Transplantation. 2009; 88: 1280.

19. Freise CE, Gillespie BW, Koffron AJ, Lok AS, Pruett TL, Emond JC et al. Recipient morbidity after living and deceased donor liver transplanta- tion: findings from the A2ALL Retrospective Cohort Study Am J Transplant. 2008; 8: 2569.

20. Tsutsumi K, Kato H, Yabe S, Mizukawa S, Seki H, Akimoto Y, et al. A comparative evaluation of treatment methods for bile duct stones after hepaticojejunostomy between percutaneous transhepatic cholangioscopy and peroral, short double-balloon enteroscopy. Ther Ad Gastroenterol. 2017;10:54-67

21. Axelrod DA, Lentine KL, Xiao H, Dzebisashvilli N, Schnitzler M Tuttle-Newhall JE, et al. National assessment of Early Biliary Complications Following Liver Transplantation: Incidence and Outcome. Liver Transpl. 2014; 20: 446-456

22. Welling TH, Heidt DG, Englesbe MJ, Magee JC, Sung RS, Campbell DA, et al. Biliary complications following liver transplantation in the model for end-stage liver disease era: Effect of donor, recipient, and technical factors. Liver Transpl. 2007:14:73-80.

23. Axelrod DA, Dzebisashvili N, Lentine KL, Xiao H, Schnitzler M, TuttleNewhall JE, et al. Variation in biliary complication rates following liver transplantation: Implication for cost and outcome. Am J Transplant. 2015;15:170-179

24. Foley DP, Fernandez LA, Leverson G, Anderson M, Mezrich J,
Sollinger HW, et al. Biliary Complications after Liver Transplantation from Donation after Cardiac Death Donors : An Analysis of Risk Factors and Long Term Outcomes from a Single Center. Ann Surg. 2011; 253:817-825

25. Esfeh JM, Eghtesad B, Hodgkinson P, Diago T, Fujiki M, Hashimoto $\mathrm{K}$, et al. Duct-to-Duct Biliary Reconstruction in Patients with Primary Sclerosing Cholangitis undergoing Liver Transplantation. HPB 2011, 13: 651-655.

26. Kaldas FM, Korayem IM, Russel TA, Agopian VG, Aziz A, DiNorcia J, et al. Assessment of Anastomotic Biliary Complication in Adult Patients Undergoing High Acuity Liver Transplant. JAMA. Surg 2019; 154:431-439

27. Rao HB, Sudhindran S P, Venu RP. Biliary strictures complicating living donor liver transplantation: Problems, novel insights and solutions. World J. Gastroenterol. 2018; 24: 2061-2072

28. Villa N, Harrison E. Management of Biliary Strictures After Liver Transplantation. Gastroenterol Hepatol (NY). 2015; 11: 316-328

29. Moy BT, Birk JW. A review on the Management of Biliary complication after orthotopic liver transplantation. J Clin TranslHepatol. 2019, 7: 61-71.

30. Kienlein S, Schoening W, Andert A, Kroy D, Neumann UP, Schmeding M. Biliary complication in liver transplantation: Impact of anastomotic technique and ischemic time on short and long term outcome. World J. Transplant 2015 24;5:300-309

31. Ren J, Wu T, Zheng BW, Tan YY, Zheng RQ, Chen GH. Application of contrast-enhanced ultrasound after liver transplantation: Current status and perspectives. World J. Gastroenterol. 2016, 28; 22: 16071616

32. Piardi T, Greget M, Audet M, Calandra G, Gheza F, Ellero B, et al. Biliary strictures after liver transplantation: is percutaneous treatment indicated?. Ann Transplant. 2011;16:5-1328-

33. Forrest EA, Reiling J, Lipka G, Fawcett J. Risk factors and clinical indicators for development of biliary strictures post liver transplant. World J Transplant . 2017, 24; 7: 349-358

34. Ostroff JW. Management of biliary complications in the liver transplant patient. Gastroenterol Hepatol (NY). 2010; 6: 264-272

35. Macías Gomez C, Dumonceau JM. Endoscopic management of biliary complication after liver transplantation: An evidence-based review. World J GastrointestEndosc. 2015, 10;7: 606-616

36. Verdonk RC, Buis Cl, van der Jagt EJ, Gouw AS, Limburg AJ, Slooff $\mathrm{MJ}$, et al. Non Anastomotic biliary strictures after liver transplantation, part 2: management, outcome, and risk factors for disease progression. Liver Transpl. 2007;13(5):725-732

37. Mourad MM, Algarni A, Liossis C, Bramhall SR. Aetiology and risk factors of ischaemic cholangiopathy after liver transplantation. World J Gastroenterol. 2014, 28; 20 : 6159-6169

38. Choo SW, Shin SW, Do YS, Liu WC, Park KB, Sung YM, et al. The balloon dilatation and large profile catheter maintenance method or the management of bile duct stricture following liver transplantation. Korean J. Radiol. 2008, 7:41-49

39. Seehofer D, Eurich D, Veltzke-Schlieker W, Neuhaus P. Biliary complications after liver transplantation: old problems and new challenges. Am J Transplant. 2013; 13: 253-265

40. Teplitsky D, UruenaTincani E, Halac E, Garriga M, Cervio G, Imventarza 0 et al. Ultrasonography, laboratory, and cholangiography correlation of biliary complications in pediatric liver transplantation. Pediatr Transplant. 2015; 19: 170-174

41. Holt AP, Thorburn D, Mirza D, Gunson B, Wong T, Haydon G. A prospective study of standardized nonsurgical therapy in the management of biliary anastomotic strictures complicating liver transplantation. Transplantation. 2007; 84: 857-863

42. Boraschi P, Donati F, Gigoni R, Filipponi F. Biliary complications following orthotopic liver transplantation: May contrast enhanced MR Cholangiography provide additional information?. Eur J Radiol. 2016; 3: 108-116

43. Pereira da Silva Aparício D, Otoch JP, de Souza Montero EF, Khan MA, Artifon ELA, et al. Endoscopic approach for management of biliary strictures in liver transplant recipients: A systematic review and meta-analysis. United European Gastroenterol J. 2017:5:827-84

44. Ramirez P, Ríos A, Sánchez Bueno F et al. ComplicacionesBiliares. 
18:247-251 in TrasplanteHepático 2nd edition, Berenguer J, and Parilla P. 2008. Elsevier España. Spanish

45. Cardelli-Leite L, Fornazari VAV, Peres RR, Salzedas-Neto AA, Gonzalez AM, Szejnfeld D,et al. The value of percutaneous transhepatic treatment of biliary strictures following pediatric liver transplantation. Radiol Bras. 2017; 50: 308-314

46. Salvalaggio PR, Whitington PF, Alonso EM, Superina RA. Presence of multiple bile ducts in the liver graft increases the incidence of biliary complications in pediatric liver transplantation. Liver Transpl. 2005;11: 161-166.

47. Prata Martin F, Kahaleh M, Ferrari AP. Management of liver transplantation biliary strictures: Results from a tertiary hospital.
World J Gastrointest. Endosc. 2015:7:747-757.

48. Zajko AB, Bron KM, Campbell WL, Behal R, Van Thiel DH, Starzl TE. Percutaneous Cholangiography and Biliary Drainage After Liver Transplantation: A Five Year Experience. GastrointestRadiol. 1987:12: $137-143$

49. Lee DW, Han J. Endoscopic management of anastomotic stricture after living-donor liver transplantation. Korean J Intern Med. 2019;34(2):261-268

50. Fakhar N, Sharifi A, ChavoshiKhamneh A, KasraianFard A, Heydar Z, Dashti SH. Safety and Efficacy of Early Oral Feeding after Liver Transplantation with Roux-en-Y Cholefochojejunostomy. Int J Org Transplant Med. 2020; 3:123-126. 